\title{
A comparative study of free oligosaccharides in the milk of domestic animals
}

\author{
Simone Albrecht ${ }^{1}$, Jonathan A. Lane ${ }^{2}$, Karina Mariño ${ }^{1} \dagger$, Khalid A. Al Busadah ${ }^{3}$, Stephen D. Carrington ${ }^{4}$, \\ Rita M. Hickey ${ }^{2}$ and Pauline M. Rudd ${ }^{1 *}$ \\ ${ }^{1}$ NIBRT GlycoScience Group, National Institute for Bioprocessing, Research and Training, Fosters Avenue, Mount Merrion, \\ Blackrock, Dublin 4, Republic of Ireland \\ ${ }^{2}$ Teagasc Food Research Centre, Moorepark, Fermoy, County Cork, Republic of Ireland \\ ${ }^{3}$ Camel Research Center, King Faisal University, Al Absa, Saudi Arabia \\ ${ }^{4}$ Veterinary Sciences Centre, University College Dublin, Belfield, Dublin 4, Republic of Ireland
}

(Submitted 10 June 2013 - Final revision received 16 October 2013 - Accepted 16 October 2013)

\section{Abstract}

The present study was conducted to obtain a comprehensive overview of oligosaccharides present in the milk of a variety of important domestic animals including cows, goats, sheep, pigs, horses and dromedary camels. Using an analytical workflow that included ultraperformance liquid chromatography-hydrophilic interaction liquid chromatography with fluorescence detection coupled to quadrupole time-of-flight MS, detailed oligosaccharide libraries were established. The partial or full characterisation of the neutral/fucosylated, phosphorylated and sialylated structures was facilitated by sequencing with linkage- and sugar-specific exoglycosidases. Relative peak quantification of the 2-aminobenzamide-labelled oligosaccharides provided additional information. Milk from domestic animals contained a much larger variety of complex oligosaccharides than was previously assumed, and thirteen of these structures have been identified previously in human milk. The direct comparison of the oligosaccharide mixtures reflects their role in the postnatal maturation of different types of gastrointestinal systems, which, in this way, are prepared for certain post-weaning diets. The potential value of animal milk for the commercial extraction of oligosaccharides to be used in human and animal health is highlighted.

\section{Key words: Domestic animal milk: Oligosaccharides: Ultra-performance liquid chromatography-hydrophilic interaction} liquid chromatography with fluorescence detection-MS: 2-Aminobenzamide: Relative quantification

Human milk and animal milk are rich sources of bioactive oligosaccharides, which are of great interest to the functional food industry. Many biological activities have been reported for certain milk oligosaccharides including prebiotic activity, anti-adhesion effects, anti-inflammatory properties, glycomemodifying activity, and a role in brain development and growth-related characteristics of intestinal cells ${ }^{(1-4)}$.

Milk oligosaccharides are typically composed of three to ten monosaccharide units, including glucose (Glc), galactose (Gal) and $N$-acetyl-glucosamine (GlcNAc) as well as fucose and sialic acids. The core unit present at the reducing end of milk oligosaccharides is either lactose ( $\mathrm{Gal}(\beta 1-4) \mathrm{Glc})$ or $N$-acetyl-lactosamine $(\mathrm{Gal}(\beta 1-4) \mathrm{GlcNAc})^{(5)}$.
As the biological activity of milk oligosaccharides is dependent on their individual structural characteristics, a detailed knowledge of their composition is necessary. Human milk is a rich source of oligosaccharides $(20 \mathrm{mg} / \mathrm{l}$ in colostrum; $12-13 \mathrm{mg} / \mathrm{l}$ in mature milk), and more than 200 structures have been identified so far ${ }^{(6,7)}$. Less is known about animal milk oligosaccharides as their concentration in milk is low. For example, the concentration of oligosaccharides in bovine colostrum is $1 \mathrm{~g} / \mathrm{l}$, whereas their concentration in mature milk is about 20 -fold less ${ }^{(8,9)}$. Using a combination of advanced analytical techniques, structural libraries of up to forty and even more than fifty bovine milk oligosaccharides $^{(10-12)}$, twenty-nine porcine milk oligosaccharides ${ }^{(13)}$, twenty caprine milk oligosaccharides ${ }^{(8)}$ and twelve

Abbreviations: 2-AB, 2-aminobenzamide; BEH, bridged ethylsiloxane/silica hybrid; DMB, 1,2-diamino-4,5-methylenedioxybenzene; FL, fucosyllactose; Gal, galactose; Glc, glucose; GlcNAc, $N$-acetyl-glucosamine; GU, glucose unit; LNnH, lacto- $N$-neo-hexaose; LNnP, lacto- $N$-novo-pentaose; LNnT, lacto- $N$ neo-tetraose; Neu5Ac, $N$-acetylneuraminic acid; Neu5Gc, $N$-glycolylneuraminic acid; SL, sialyllactose; SLN, sialylated $N$-acetyllactosamine; UPLC-HILIC-FLD, ultra-performance liquid chromatography-hydrophilic interaction liquid chromatography with fluorescence detection.

*Corresponding author: P. M. Rudd, fax +353 12158 116, email pauline.rudd@nibrt.ie

† Present address: Laboratorio de Glicómica Funcional y Molecular, Instituto de Biología y Medicina Experimental (IByME), Vuelta de Obligado 2490, CP 1, CP 1428 Ciudad de Buenos Aires, Argentina 
oligosaccharides from camel milk have recently been established ${ }^{(14)}$. A few oligosaccharide structures have also been assigned for equine and ovine $\operatorname{milk}^{(15,16)}$. In contrast to human milk, the content of fucosylated oligosaccharides is rather low in the milk of domestic animal species. Most of the oligosaccharides in animal milk are sialylated, containing $\mathrm{N}$-acetylneuraminic acid (Neu5Ac) and/or $\mathrm{N}$-glycolylneuraminic acid (Neu5Gc) ${ }^{(5,17)}$

The different analytical methods used to study milk oligosaccharides make comparative analysis of oligosaccharide profiles difficult. Therefore, we carried out a study to obtain a comprehensive overview of oligosaccharides present in the milk of cows, goats, sheep, pigs, horses and dromedary camels. A combination of weak anion-exchange chromatography, ultra-performance liquid chromatography-hydrophilic interaction liquid chromatography with fluorescence detection (UPLC-HILIC-FLD) and complementary quadrupole timeof-flight MS as well as exoglycosidase sequencing allowed for the determination of the oligosaccharide sequences and linkages as well as their relative quantification. A direct comparison of the oligosaccharide mixtures could contribute to a better understanding of possible differences in their biological effects and highlight the potential value of animal milk for commercial oligosaccharide extraction.

\section{Materials and methods}

\section{Standards and chemicals}

Milk oligosaccharide standards ( $2^{\prime}$-fucosyllactose ( $2^{\prime}$-FL), 3-FL, $3^{\prime}$-sialyllactose ( $3^{\prime}$-SL), $6^{\prime}$-SL, $6^{\prime}$-sialylated $N$-acetyllactosamine ( $6^{\prime}$-SLN), lacto- $N$-neo-tetraose (LNnT), lacto- $N$-tetraose (LNT), lacto- $N$-neo-hexaose (LNnH) and lacto- $N$-hexaose (LNH)) were purchased from Carbosynth Limited. Gal( $\beta 1-4) \mathrm{Gal}$ $(\beta 1-4) \mathrm{Glc}, \mathrm{Gal}(\beta 1-3) \mathrm{Gal}(\beta 1-4) \mathrm{Glc}$ and $\mathrm{Gal}(\beta 1-6) \mathrm{Gal}(\beta 1-4)$ Glc were purchased from Dextra Laboratories. Chemicals and solvents were obtained from Sigma-Aldrich and were of LC or LC-MS grade, respectively.

\section{Isolation of animal milk oligosaccharides}

Bovine colostrum from Holstein-Friesian cows and porcine colostrum from Landrace pigs were obtained on-site at Teagasc Food Research Centre, Moorepark (Fermoy, Cork, Ireland). Equine colostrum from Draught foster mares was kindly provided by Coolmore Stud (Fethard, County Tipperary), while ovine colostrum from Scottish black-faced mountain sheep was kindly donated by Cashel Irish Farmhouse Cheese Makers (Fethard, County Tipperary). Mature milk from goats was kindly donated by Ardsallagh Goat Farm (Carrigtwohill, County Cork). Mature milk from dromedary camels was kindly provided by King Faisal University (Saudi Arabia). After collection, the milk samples $(n \geq 3)$ from each animal species were pooled. The isolation of oligosaccharides from pooled animal milk and colostrum samples was carried out as described previously ${ }^{(11)}$. Briefly, the samples were defatted by centrifugation at $4^{\circ} \mathrm{C}(3850 \mathrm{~g}$, $20 \mathrm{~min}, 4^{\circ} \mathrm{C}$; Sorvall RC6 plus $\left.{ }^{\circledR}\right)$. Caseins were precipitated at
$\mathrm{pH}$ 4.6. After neutralisation, large peptides were removed by ultrafiltration $\left(5 \mathrm{kDa}\right.$ molecular-weight cut-off, Millipore ${ }^{\circledR}$ Helicon S10 Spiral Cartridge; Millipore). The permeates were freeze-dried and stored at $-80^{\circ} \mathrm{C}$ until further processing. To remove lactose and residual peptides, the extracts were resolubilised in MilliQ ${ }^{\circledR}$ water and applied onto a Sephadex G-25 column (Pharmacia; $92 \times 2.6 \mathrm{~cm}$ ). Elution was carried out with deionised water $(5 \mathrm{ml} / \mathrm{min})$. Fractions were monitored for peptides according to the method of Bradford ${ }^{(18)}$, and the lactose content was determined by high-performance anion-exchange chromatography ${ }^{(11)}$. Fractions low in peptide and lactose content were pooled and used for further characterisation.

\section{Fluorescent labelling of animal milk oligosaccharides with 2-aminobenzamide}

Animal milk oligosaccharides were fluorescently derivatised via reductive amination with 2 -aminobenzamide (2-AB) and sodium cyanoborohydride in $30 \%(\mathrm{v} / \mathrm{v})$ acetic acid-dimethyl sulphoxide. A volume of $5 \mu \mathrm{l}$ of labelling mixture was used per approximately $5 \mu \mathrm{g}$ oligosaccharides and incubated at $65^{\circ} \mathrm{C}$ for $2 \mathrm{~h}$. The samples were purified by ascending paper chromatography in acetonitrile (ACN) ${ }^{(19)}$.

\section{Fractionation of neutral and acidic oligosaccharides by weak anion-exchange chromatography}

Weak anion-exchange chromatography was carried out on a Waters BioSuite ${ }^{\mathrm{TM}}$ DEAE anion-exchange column ( $7.5 \times 75 \mathrm{~mm}$; Waters), which was installed on a Waters 2795 Alliance system with a 2475 fluorescence detector (excitation wavelength $\left(\lambda_{\mathrm{ex}}\right) 330 \mathrm{~nm}$; emission wavelength $\left(\lambda_{\mathrm{em}}\right)$ $420 \mathrm{~nm}$ ). Solvent A was composed of $20 \%$ acetonitrile and solvent $\mathrm{B}$ was composed of $0 \cdot 1 \mathrm{M}$-ammonium acetate buffer, $\mathrm{pH}$ $7 \cdot 0$, in $20 \%(\mathrm{v} / \mathrm{v})$ acetonitrile. The elution conditions were $100 \%$ solvent A $(0-5 \mathrm{~min})$, a linear gradient of $100-0 \%$ solvent A (5-20 min), and column regeneration and cleaning in $100 \%$ solvent B $(20-22.5 \mathrm{~min})$ and $100 \%$ solvent $\mathrm{A}$ $(23-30 \mathrm{~min})$. The flow rate applied was $0.75 \mathrm{ml} / \mathrm{min}$. The samples were stored at $5^{\circ} \mathrm{C}$ before injection, and the column temperature was kept at $25^{\circ} \mathrm{C}$. The samples were injected in water, and a fetuin- $N$-glycan standard was used for calibration.

\section{Digestion of oligosaccharides with exoglycosidases and alkaline phosphatase}

Sugar- and linkage-specific exoglycosidases as well as an alkaline phosphatase were used to determine the fine structure of the milk oligosaccharides. Alkaline phosphatase derived from calf intestine (EC 3.1.3.1), $20 \mathrm{mU} / \mathrm{ml}$, was purchased from Roche. The exoglycosidases used (all purchased from ProZyme) were as follows: A. ureafaciens $\alpha(2-3 / 6 / 8)$ sialidase (EC 3.2.1.18), $1-2 \mathrm{U} / \mathrm{ml} ; \quad S$. pneumoniae $\alpha(2-3)$-sialidase recombinant in Escherichia coli (EC 3.2.1.18), $1 \mathrm{U} / \mathrm{ml}$; bovine kidney $\alpha(1-2 / 3 / 4)$ fucosidase (EC 3.2.1.51), $1 \mathrm{U} / \mathrm{ml}$; almond meal $\alpha(1-3 / 4)$ fucosidase (EC 3.2.1.111), $3 \mathrm{mU} / \mathrm{ml} ; \beta(1-3 / 4)$ galactosidase from bovine testis (EC 3.2.1.23), $2 \mathrm{U} / \mathrm{ml}$; 
$\beta(1-4)$-galactosidase from $S$. pneumoniae (EC 3.2.1.23), $80 \mathrm{mU} / \mathrm{ml} ; \alpha(1-3 / 4)$-galactosidase from coffee bean (EC 3.2.1.22), $0.5 \mathrm{U} / \mathrm{ml}$; chicken liver $\alpha(1-3)-N$-acetylgalactosaminidase (EC 3.2.1.49), $0.7 \mathrm{U} / \mathrm{ml}$; jack bean $\beta(1-2 / 3 / 4 / 6)-N$-acetylhexosaminidase (EC 3.2.1.52), $10 \mathrm{mU} / \mathrm{ml}$. All the enzymatic digestions were carried out using 2-AB-labelled milk oligosaccharides in $10 \mu \mathrm{l}$ of solution containing enzymes at standard concentrations in the manufacturer's recommended buffers for $16 \mathrm{~h}$ at $37^{\circ} \mathrm{C}$. After digestion, the enzymes were removed from the samples by filtration through a $10 \mathrm{~K}$ microcentrifuge filter (Pall Life Sciences). The filtrate was dried in a Speed Vac and resuspended for analysis by UPLC-HILIC-FLD-(MS).

\section{Oligosaccharide profiling by ultra-performance liquid chromatography-hydrophilic interaction liquid chromatography with fluorescence detection analysis}

The 2-AB-labelled animal milk oligosaccharide mixtures were separated by ultra-performance liquid chromatography with fluorescence detection using a Waters BEH Glycan column $(150 \times 2.1 \mathrm{~mm}, \quad 1.7 \mu \mathrm{m}$ BEH (bridged ethylsiloxane/silica hybrid) particles), which was installed on a Waters H-Class instrument, consisting of a quaternary solvent manager, sample manager and fluorescence detector. Solvent A was composed of a 50 mm-ammonium formate buffer, $\mathrm{pH} 4 \cdot 4$, and solvent $\mathrm{B}$ was acetonitrile. The elution conditions were $12 \%$ solvent A $(0-1.5 \mathrm{~min}), 12-47 \%$ solvent A $(1.5-35 \mathrm{~min})$, $70 \%$ solvent A (35.5-36 min) and $12 \%$ solvent A (36.5-40 min). The flow rate was $0.56 \mathrm{ml} / \mathrm{min}$. The injection volume was $10 \mu \mathrm{l}$, and the samples were prepared in $80 \%(\mathrm{v} / \mathrm{v})$ acetonitrile. The samples were stored at $5^{\circ} \mathrm{C}$ before injection, and the separation temperature was $25^{\circ} \mathrm{C}$. The fluorescence detection wavelengths were $\lambda_{\mathrm{ex}}=330 \mathrm{~nm}$ and $\lambda_{\mathrm{em}}=420 \mathrm{~nm}$ with a data collection rate of $20 \mathrm{~Hz}$. A dextran hydrolysate ladder was used to convert retention times into glucose unit (GU) values. All the data were processed using the Waters Empower 3 chromatography workstation software.

Characterisation of oligosaccharides by ultra-performance liquid chromatography-hydrophilic interaction liquid chromatography with fluorescence detection-MS/MS analysis

UPLC-HILIC-FLD-MS and mass fragmentation (MS/MS) analysis of the 2-AB-labelled animal milk oligosaccharide mixtures was carried out on a Waters Acquity instrument with fluorescence detection connected to a Waters XEVO QTOF instrument. The Waters Acquity system consists of a binary solvent manager, sample manager and fluorescence detector and is equipped with a Waters BEH Glycan column $(150 \times 1 \mathrm{~mm}, 1.7 \mu \mathrm{m} \mathrm{BEH}$ particles). The solvents, elution conditions, fluorescence detector settings, injection volume, sample preparation method, sample storage conditions and column temperature were the same as those used for the UPLC-HILIC-FLD analysis. MS analysis was carried out in negative mode. The source capillary voltage was set to $2 \mathrm{kV}$ and the source temperature was $100^{\circ} \mathrm{C}$. The collision energy ramp for mass fragmentation was $30-42 \mathrm{~V}$. The mass range for MS was set to $m / z 400-2000$ and that for MS/MS was set to $m / z$ 100-2000. Data were processed using MassLynx software version 4.1 (Waters).

\section{Sialic acid speciation}

Sialic acids were released by mild acid hydrolysis ( $2 \mathrm{M}$-acetic acid, $80^{\circ} \mathrm{C}, 2 \mathrm{~h}$ ). To a $5 \mu \mathrm{l}$ aliquot of the released solution, $20 \mu \mathrm{l}$ of DMB (1,2-diamino-4,5-methylenedioxybenzene) labelling solution (DMB in mercaptoethanol and sodium dithionite; Ludger) were added, and the mixture was incubated for $3 \mathrm{~h}$ at $50^{\circ} \mathrm{C}$ in the dark. The reaction was quenched by adding $475 \mu \mathrm{l}$ of water. The labelled samples were diluted 1:10 and analysed using reversed-phase UPLC on a Waters XBridge BEH C18 $(150 \times 2.1 \mathrm{~mm}$ inner diameter, $3.5 \mu \mathrm{m}$ column $)$ with fluorescence detection $\left(\lambda_{\mathrm{ex}}=343 \mathrm{~nm}\right.$; $\left.\lambda_{\mathrm{em}}=448 \mathrm{~nm}\right)$.

\section{Results}

Analysis of milk oligosaccharides by ultra-performance liquid chromatography-hydrophilic interaction liquid chromatography with fluorescence detection analysis

In the present study, oligosaccharides were extracted from pooled colostrum samples from cows, sheep, pigs and horses and pooled mature milk samples from goats and dromedary camels.

A global overview of the UPLC-HILIC-FLD profiles of the 2-AB fluorescently labelled milk oligosaccharides from the different animal species is shown in Fig. 1. Retention times were converted into GU values, enabling the independent comparison of different oligosaccharide profiles and the incorporation of the structures in our public access database (GlycoBase 3.2.2) ${ }^{(20)}$. Distinct and well-separated profiles were obtained for all the species. The profiles of all the milk oligosaccharides from domestic animals were dominated by one or few sialyllactose isomers (A6, A9, A11 and A15; their structural characterisation is described below and in Table 2). Lactose is the main carbohydrate component in domestic animal milk ${ }^{(5)}$. Before fluorescent labelling and analysis, the concentration of lactose in the samples was reduced by gel filtration. This procedure was essential to gain more signal intensity for the less-abundant milk oligosaccharides. As disaccharides other than lactose were also removed during sample preparation, they were not considered for characterisation and quantification.

\section{Prefractionation and structural analysis of animal milk oligosaccharides}

Detailed analysis of the complex oligosaccharide mixtures required subfractionation into neutral and acidic oligosaccharide pools. Therefore, the 2-AB-labelled oligosaccharide mixtures were subjected to preparative weak anion-exchange chromatography before the UPLC-HILIC-FLD analysis. Fluorescent labelling is stoichiometric and allows for relative quantification. The relative proportions of neutral and acidic oligosaccharides in the subfractions were determined by 
peak quantification relative to the total baseline-integrated peak area set to $100 \%$ (Tables 1 and 2). Subsequently, the relative proportions obtained for the subfractions were translated into total profiles to calculate the overall proportion of neutral and sialylated oligosaccharides (Table 4). The total oligosaccharide pools from the milk of all the domestic animals were composed of approximately $80-90 \%$ acidic oligosaccharides (Table 4).

By means of exoglycosidase sequencing and subsequent analysis of the oligosaccharide profiles by the UPLC-HILICFLD-(MS/MS) analysis, twenty-nine neutral, forty-five sialylated and three phosphorylated structures were identified in animal milk (Tables 1-3). Detailed information on the specific mode of action of exoglycosidases on milk oligosaccharides has been reported in Mariño et al. ${ }^{(11)}$. Characteristic shifts in GU values upon exoglycosidase digestion allowed for detailed structural assignment of the animal milk oligosaccharides ${ }^{(11)}$. Of the oligosaccharide structures assigned for domestic animal milk, thirteen have been identified previously in human milk ${ }^{(6,7)}$ and are highlighted in Tables 1 and 2 .

\section{Structural characterisation of neutral oligosaccharides from animal milk}

Galactotrioses and galactotetraose. Galactotrioses ( $\mathrm{Gal}(\alpha 1-3)$ Gal $(\beta 1-4)$ Glc, $\quad$ N6, Gal( $\beta 1-3)$ Gal $(\beta 1-4) G l c, \quad$ N7, and

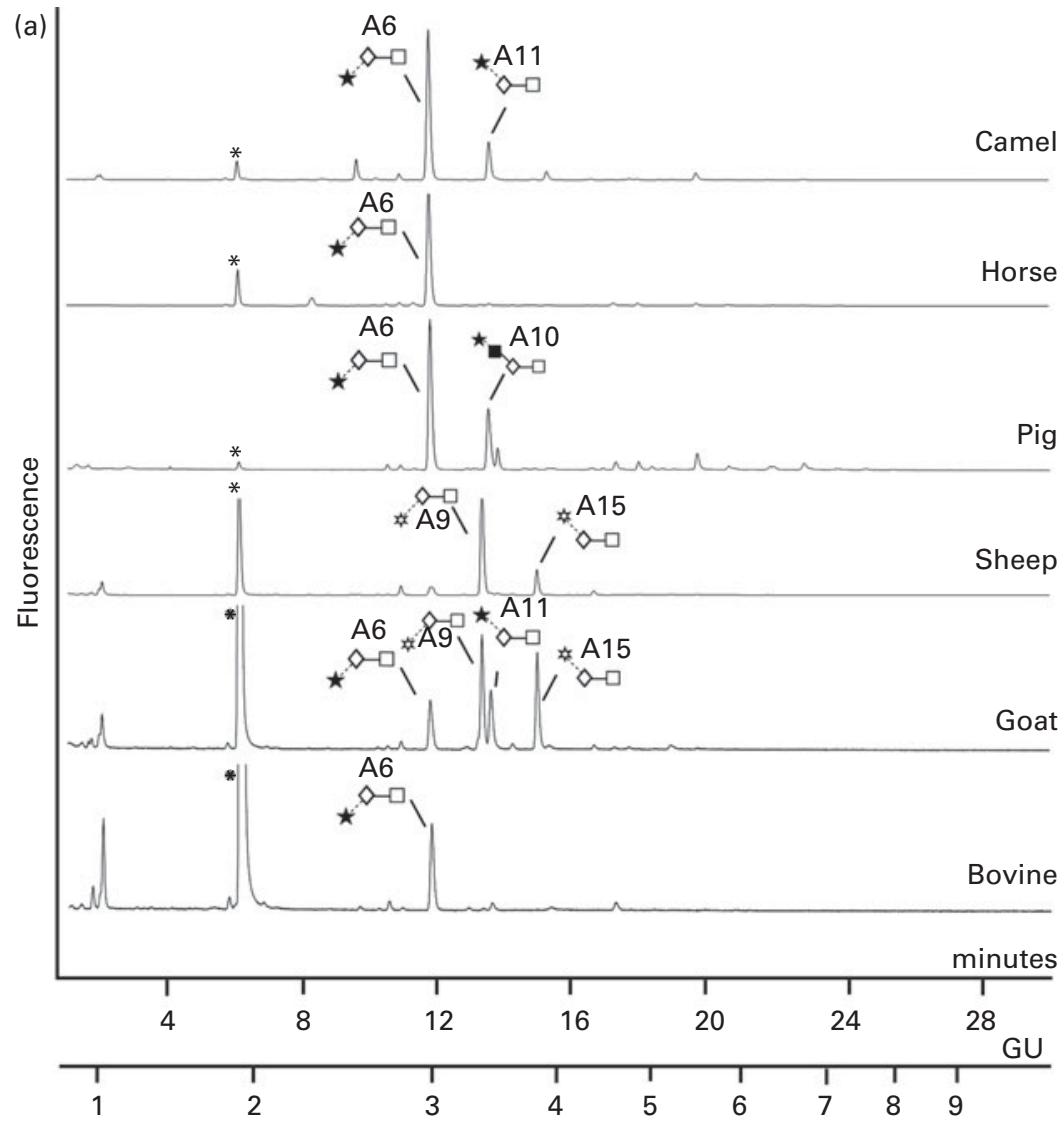

(b)

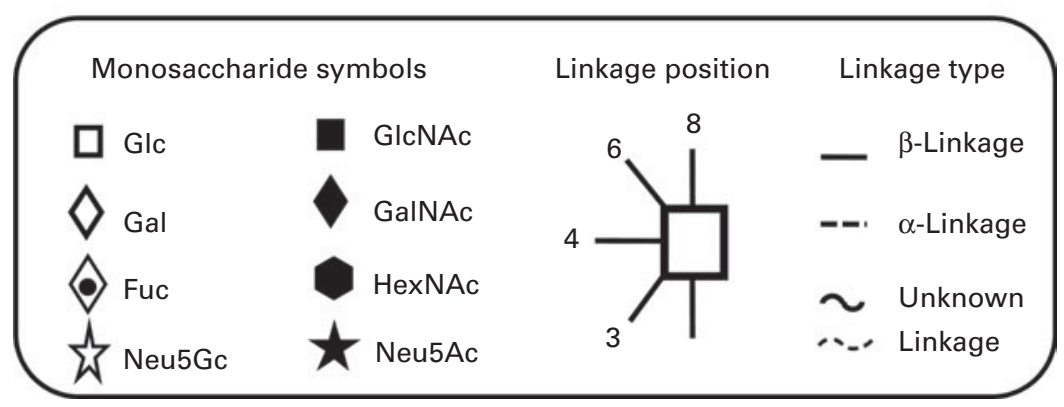

Fig. 1. (a) Ultra-performance liquid chromatography-hydrophilic interaction liquid chromatography with fluorescence detection profiles of 2-aminobenzamidelabelled free oligosaccharides from the milk of domestic animals. Major peaks are assigned according to Table 2 and their structures are given using (b) the Oxford symbol nomenclature ${ }^{(30)}$. ${ }^{*}$ Lactose (removed during sample preparation). GU, glucose unit reference values; Glc, glucose; GlcNAc, $N$-acetyl-glucosamine; Gal, galactose; GalNAc, $N$-acetyl-galactosamine; Fuc, fucose; HexNAc, $N$-acetyl-hexosamine; Neu5Gc, $N$-glycolylneuraminic acid; Neu5Ac, $N$-acetylneuraminic acid. 


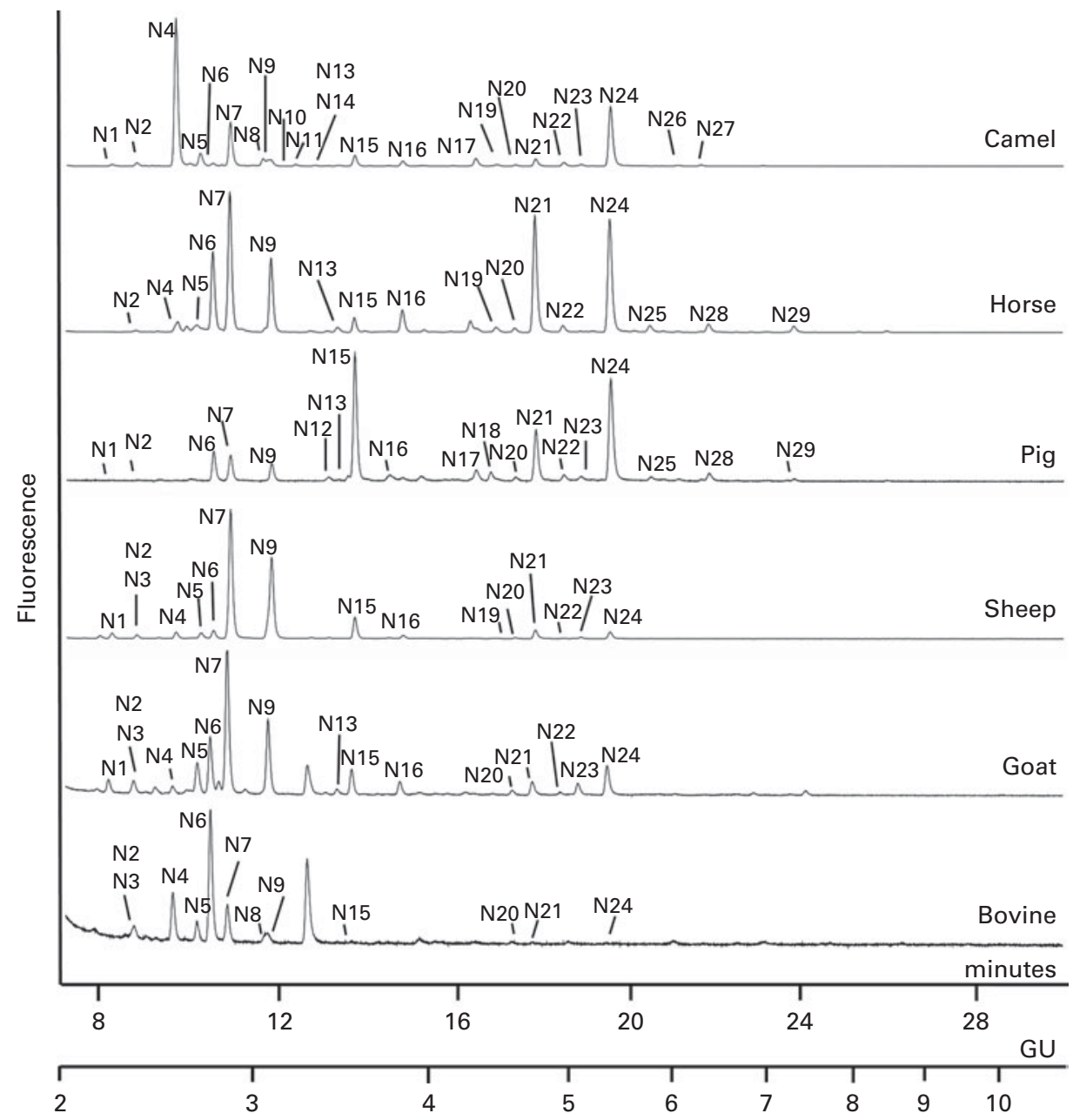

Fig. 2. Ultra-performance liquid chromatography-hydrophilic interaction liquid chromatography with fluorescence detection profiles of 2-aminobenzamide-labelled neutral oligosaccharide pools from the milk of domestic animals. Major peaks are assigned according to Table 1. GU, glucose unit reference values.

Gal( $\beta 1-6)$ Gal( $\beta 1-4)$ Glc, N9, with N7 and N9 being identified previously in human $\mathrm{milk}^{(7)}$ ) are the most abundant structures in the total neutral oligosaccharide pool. $\alpha$-Galactotriose was selectively degraded by an $\alpha$-specific galactosidase from coffee bean. Due to limitations in enzyme specificities, the $(\beta 1-3 / 6)$-linked galactotrioses were identified by their respective standards. The $(\beta 1-4)$-linked galactotriose (GU 2.74 ) was not detected in the milk of any of the animals. Trace amounts of an unknown galactotriose isomer (N10) and a galactotetrasaccharide (N13) were detected.

$N$-acetyl-bexosaminyl-lactoses. GalNAc $(\alpha 1-3) \mathrm{Gal}(\beta 1-4) \mathrm{Glc}$ (N4) and GlcNAc $(\beta 1-3) \operatorname{Gal}(\beta 1-4)$ Glc (N5) were identified with a $\beta$ - $N$-acetylhexosaminidase-specific enzyme from jack bean and an $\alpha$ - $N$-acetylgalactosaminidase from chicken liver.

Lacto-N-neo-tetraose and iso-lacto- $N$-neo-tetraose. LNnT $(\operatorname{Gal}(\beta 1-4) \operatorname{GlcNAc}(\beta 1-3) \mathrm{Gal}(\beta 1-4) \mathrm{Glc}, \mathrm{N} 15)$, which is also present in human $\operatorname{milk}^{(7)}$, and iso-LNnT $(\mathrm{Gal}(\beta 1-4)$ GlcNAc $(\beta 1-6)$ Gal $(\beta 1-4)$ Glc, N16) were identified by their characteristic GU shifts following enzymatic digestion with a $(\beta 1-4)$-specific galactosidase from $S$. pneumoniae.
Lacto- $N$-novo-pentaose and lacto- $N$-neo-hexaose. Gal( $\beta 1-4)$ GlcNAc $(\beta 1-6)(\operatorname{GlcNAc}(\beta 1-3)) \operatorname{Gal}(\beta 1-4)$ Glc (N20), lacto- $N$ novo-pentaose I (LNnP I; Gal $(\beta 1-4) \operatorname{GlcNAc}(\beta 1-6)(\operatorname{Gal}(\beta 1-3))$ $\mathrm{Gal}(\beta 1-4) \mathrm{Glc}, \mathrm{N} 21)$ and $\mathrm{LNnH}(\mathrm{Gal}(\beta 1-4) \mathrm{GlcNAc}(\beta 1-6)$ $(\operatorname{Gal}(\beta 1-4)$ GlcNAc $(\beta 1-3)) G a l(\beta 1-4) G l c, N 24)$, the latter of which is present in human milk ${ }^{(7)}$, were degraded to their characteristic tetrasaccharide and/or trisaccharide cores by a $(\beta 1-4)$-specific galactosidase from $S$. pneumoniae and a $(\beta 1-3 / 4)$-specific galactosidase from bovine testis. Structural isomers (N18, N19 and N22) and an $\mathrm{N}$-acetyl-lactosamine derivative of $\mathrm{LNnH}$ (N23) were also observed with some of the structures potentially being linear oligosaccharides, such as para-LNnH (Gal $(\beta 1-4) \operatorname{GlcNAc}(\beta 1-3) \mathrm{Gal}(\beta 1-4) \mathrm{GlcNAc}$ $(\beta 1-3) \mathrm{Gal}(\beta 1-4) \mathrm{GlC})$ in human milk ${ }^{(7)}$.

$\alpha$-Galactosylated lacto- $N$-novo-pentaose and lacto- $N$-neobexaose. $\alpha$-Galactosylated LNnP (N25) and mono- $\alpha$-galactosylated and di- $\alpha$-galactosylated $\mathrm{LNnH}$ (N28 and N29) were identified by digestion with the $\alpha$-specific galactosidase from coffee bean. $\alpha$-Galactosylated oligosaccharides are not present in human milk $^{(7)}$, but di- $\alpha$-galactosylated $\mathrm{LNnH}$ has been observed previously in the milk from polar bears ${ }^{(21)}$. 
Fucosylated oligosaccharides. In contrast to human milk, merely eight neutral fucosylated oligosaccharides were identified in the total neutral oligosaccharide pool from animal milk, including fucosyllactoses (2'-FL (Fuc $(\alpha 1-2) \mathrm{Gal}(\beta 1-4)$ Glc, N1) and 3-FL $(\operatorname{Gal}(\beta 1-4)(\operatorname{Fuc}(\alpha 1-3))$ Glc, N2)), fucosyl$N$-acetyl-lactosamine (3-FLN $(\operatorname{Gal}(\beta 1-4)(\operatorname{Fuc}(\alpha 1-3))$ GlcNAc, N3)), fucosyl-galactosaminyllactose $(\operatorname{GalNAc}(\alpha 1-3)(\operatorname{Fuc}(\alpha 1-2))$ Gal( $\beta 1-4)$ Glc, N8), fucosylated galactotriose (N11), fucosylated LNnT (lacto- $N$-fucopentaose III; Gal $(\beta 1-4)$ (Fuc $(\alpha 1-3)$ ) GlcNAc $(\beta 1-3) \mathrm{Gal}(\beta 1-4) \mathrm{Glc}, \mathrm{N} 17)$ and fucosylated $\mathrm{LNnH}$ (FLNnH; N26 and N27) isomers. Except N3, N8 and N11, these fucosylated structures have also been reported for human $\operatorname{milk}^{(7)}$. The fucosylated structures were identified with the aid of an ( $\alpha 1-3 / 4)$-specific fucosidase from almond meal and an $\alpha(1-2 / 3 / 4)$-specific fucosidase from bovine kidney

\section{Structural characterisation of acidic oligosaccharides from animal milk}

Digestion of the samples with a sialidase from $A$. ureafaciens specific for $(\alpha 2-3 / 6 / 8)$-linkages and a recombinant sialidase from $S$. pneumoniae specific for $(\alpha 2-3)$-linkages provided linkage information on the underlying acidic structure.
Due to the differences in mass $(m / z)$, MS analysis could be used to differentiate between Neu5Ac- and Neu5Gccontaining oligosaccharides $(\mathrm{m} / \mathrm{z}$ Neu5Ac: $309 \cdot 11 ; \mathrm{m} / \mathrm{z}$ Neu5Gc: $325 \cdot 10)$. The MS charge state of multisialylated oligosaccharides indicates whether the Neu5Ac/Neu5Gc residues are attached to different sugar units in the oligosaccharide (doubly charged ions; $[\mathrm{M}-2 \mathrm{H}]^{2-}$ ) or are sequentially attached (singly charged ions; $[\mathrm{M}-\mathrm{H}]^{-}$).

The sialic acid composition of the animal milk oligosaccharides was determined by reversed-phase UPLC-UV after sample hydrolysis and DMB labelling. Major differences in the composition between animal species were observed. The acidic oligosaccharides from the milk of cows, pigs, horses and camels were decorated to $\geq 98 \%$ with Neu5Ac, while Neu5Gc contributed to 64 and $94 \%$ of the total sialic acid content in those from the milk of goats and sheep, respectively (Table 4). Neu5Ac is the sole sialic acid in human milk ${ }^{(7)}$.

Sialylated lactose and $\mathrm{N}$-acetyl-lactosamine. The total acidic oligosaccharide pool from animal milk was dominated by two pairs of sialylated lactose isomers, $3^{\prime}-\mathrm{SL} / 6$ '-SL (Neu5Ac $(\alpha 2-3)$ Gal( $(\beta 1-4)$ Glc, A6/Neu5Ac( $\alpha 2-6)$ Gal $(\beta 1-4)$ Glc, A11) and $3^{\prime} \mathrm{GL} / 6^{\prime} \mathrm{GL}$ (Neu5Gc( $\left.\alpha 2-3\right) \mathrm{Gal}(\beta 1-4) \mathrm{Glc}$, A9/Neu5Gc( $\left.\alpha 2-6\right)$ Gal( $\beta 1-4)$ Glc, A15). In human milk, $3^{\prime}-\mathrm{SL} / 6^{\prime}-\mathrm{SL}$ are also important components, but in contrast to animal milk, the

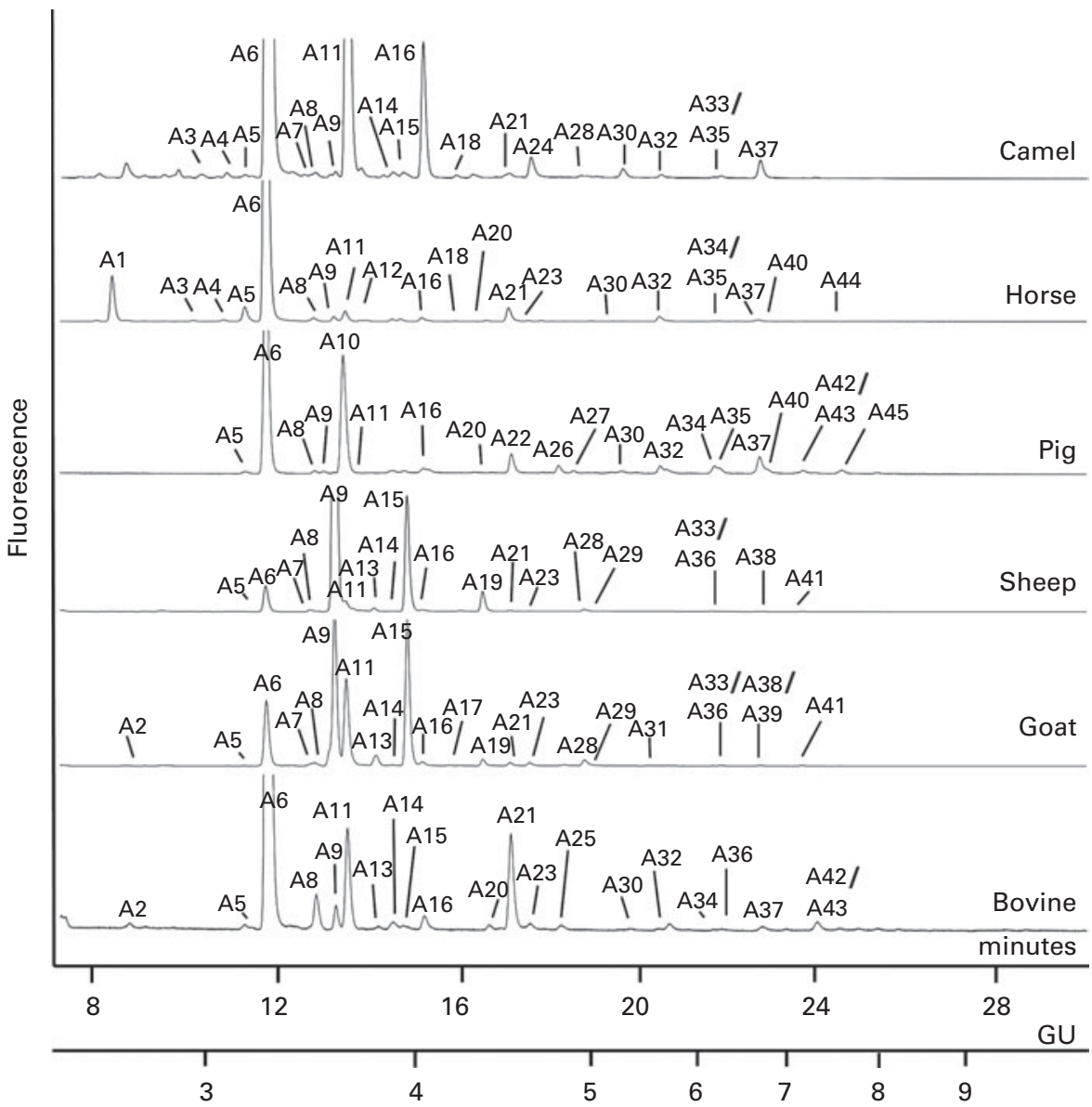

Fig. 3. Ultra-performance liquid chromatography-hydrophilic interaction liquid chromatography with fluorescence detection profiles of 2-aminobenzamide-labelled acidic oligosaccharide pools from the milk of domestic animals. Major peaks are assigned according to Table 2 . GU, glucose unit reference values. 
Table 1. Structures and their relative abundances in the neutral oligosaccharide pools from animal milk

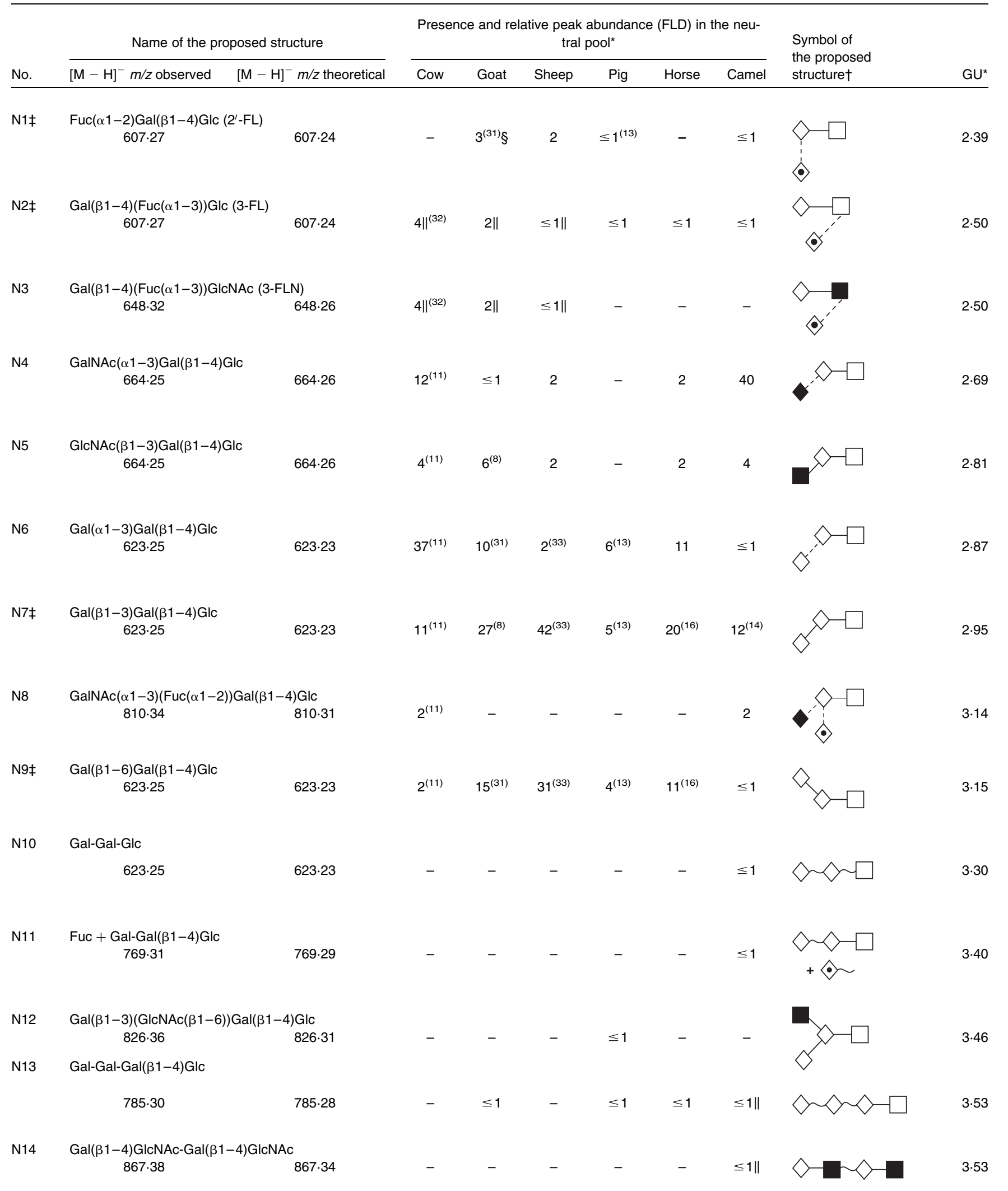


Table 1. Continued

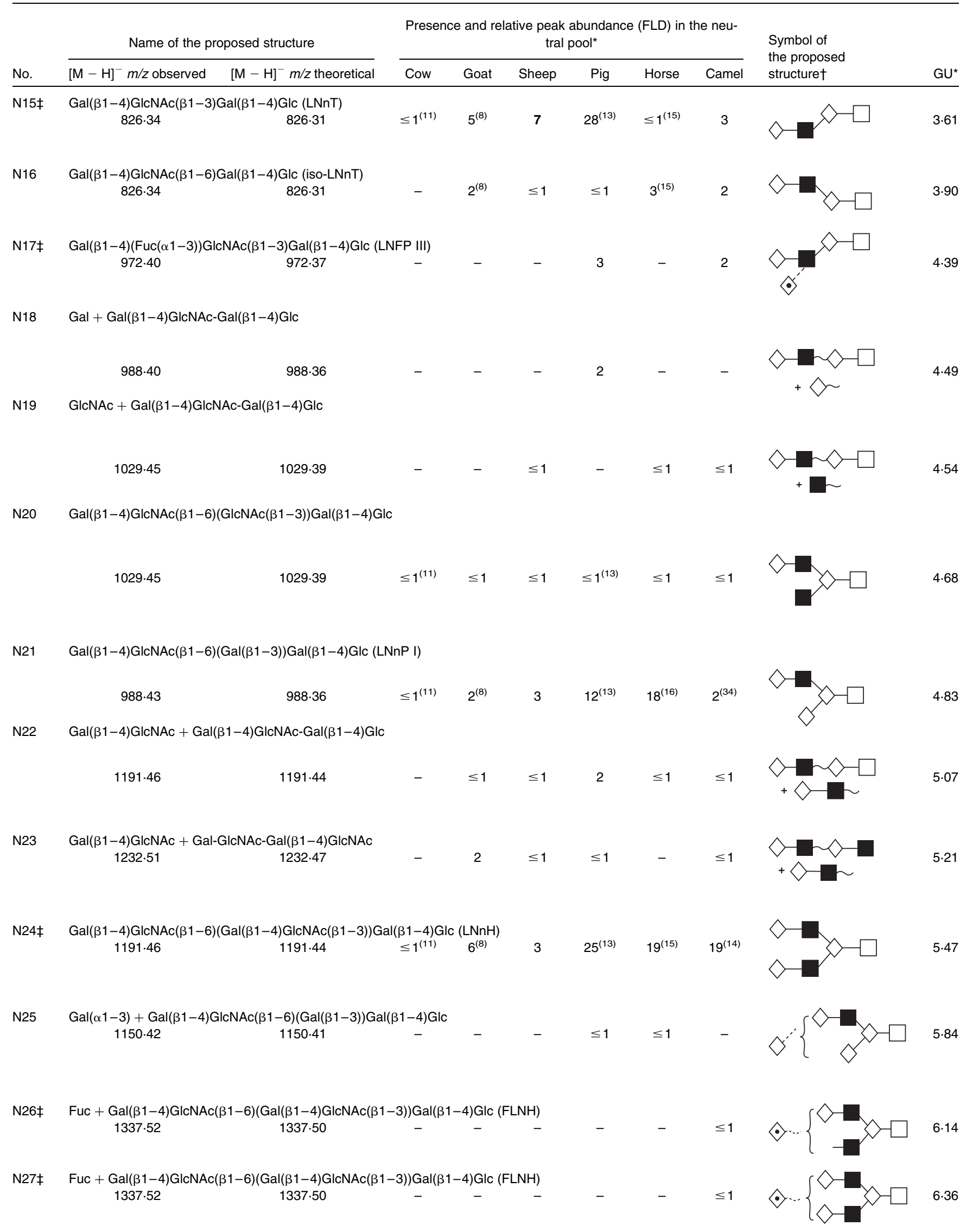


Table 1. Continued

\begin{tabular}{|c|c|c|c|c|c|c|c|c|c|c|}
\hline \multirow[b]{2}{*}{ No. } & \multicolumn{2}{|c|}{ Name of the proposed structure } & \multicolumn{6}{|c|}{$\begin{array}{l}\text { Presence and relative peak abundance (FLD) in the neu- } \\
\text { tral pool }^{*}\end{array}$} & \multirow{2}{*}{$\begin{array}{l}\text { Symbol of } \\
\text { the proposed } \\
\text { structuret }\end{array}$} & \multirow[b]{2}{*}{$\mathrm{GU}^{*}$} \\
\hline & {$[\mathrm{M}-\mathrm{H}]^{-} \mathrm{m} / \mathrm{z}$ observed } & {$[\mathrm{M}-\mathrm{H}]^{-} \mathrm{m} / \mathrm{z}$ theoretical } & Cow & Goat & Sheep & Pig & Horse & Camel & & \\
\hline N28 & $\begin{array}{c}\mathrm{Gal}(\alpha 1-3)+\mathrm{Gal}(\beta 1-4) \\
1353.55\end{array}$ & $\begin{array}{c}\mathrm{cNAc}(\beta 1-6)(\mathrm{Gal}(\beta 1-4) \mathrm{Glc} \\
1353.49\end{array}$ & $\begin{array}{c}c(\beta 1- \\
-\end{array}$ & $\underset{-}{\operatorname{aral}(\beta 1-}$ & Glc & 2 & $\leq 1$ & - & & 6.42 \\
\hline N29 & $\begin{array}{c}2 \mathrm{Gal}(\alpha 1-3)+\mathrm{Gal}(\beta 1-4 \\
1515.55\end{array}$ & $\begin{array}{c}\operatorname{lcNAc}(\beta 1-6)(\mathrm{Gal}(\beta 1-4) \mathrm{G} \\
1515.55\end{array}$ & $\operatorname{Ac}(\beta 1$ & Gal( $\beta 1$ & 4)Glc & $\leq 1$ & $\leq 1$ & - & & 7.36 \\
\hline
\end{tabular}

FLD, fluorescence detection; GU, glucose unit reference values; Fuc, fucose; Gal, galactose; Glc, glucose; FL, fucosyllactose; GlcNAc, N-acetyl-glucosamine; FLN, fucosyl$\mathrm{N}$-acetyl-lactosamine; GalNAc, $\mathrm{N}$-acetylgalactosamine; LNnT, lacto- $\mathrm{N}$-neo-tetraose; LNFP, lacto-N-fucopentaose; LNnP, lacto- $\mathrm{N}$-novo-pentaose; LNnH, lacto- $N$-neo-hexaose; $\mathrm{FLNH}$, fucosylated lacto- $N$-hexaose.

${ }^{*}$ Relative peak area and GU correspond to the average (av) observed for the respective species, which were each analysed in duplicate or triplicate $\left(\Delta \mathrm{GU} \mathrm{U}_{(\mathrm{av})} \leq 0.03\right)$.

†Oxford symbol nomenclature ${ }^{(30)}$ (Fig. 1(b)).

$\ddagger$ Structures also reported for human milk(6,7)

$\S$ Most recent reference was included for identified structures that were previously assigned for the respective milk samples.

\| Co-eluting structures; relative abundance accounts for both structures.

$6^{\prime}$ isomer is more abundant than the $3^{\prime}$ isomer $^{(7)}$. Animal milk additionally contained two pairs of SLN isomers $\left(3^{\prime} / 6^{\prime}-\right.$ SLN (Neu5Ac $(\alpha 2-3)$ Gal $(\beta 1-4)$ GlcNAc, A5/Neu5Ac( $\alpha 2-6)$ Gal( $\beta 1-4)$ GlcNAc, A8) and $3^{\prime} / 6^{\prime} \mathrm{GLN}(\mathrm{Neu} 5 \mathrm{Gc}(\alpha 2-6) \mathrm{Gal}(\beta 1-4) \mathrm{GlcNAc}$, $\mathrm{A} 7 / \mathrm{Neu} 5 \mathrm{Gc}(\alpha 2-6) \mathrm{Gal}(\beta 1-4) \mathrm{GlcNAc}, \mathrm{A} 13))$ as well as five disialylated lactoses/ $N$-acetyl-lactosamines (A20, A21 A23, A25, A28 and A31). The presence of two acetylated sialyllactose isomers (A1 and A2) was confirmed by mass fragmentation, and traces of a fucosyl-sialyllactose (Neu5Ac( $\alpha 2-3) \mathrm{Gal}(\beta 1-4)$ (Fuc $(\alpha 1-3))$ Glc, A12) were identified by enzymatic digestion.

Sialylated galactotriose and hexosaminyl-lactose. In animal milk, two pairs of sialylated galactotriose isomers $\left(3^{\prime \prime} / 6^{\prime}-\mathrm{Neu}\right.$ 5Ac-galactotriose (A16 and A18) and $3^{\prime \prime} / 6^{\prime}$-Neu5Gc-galactotriose (A17 and A19)) and two disialylgalactotrioses (3"-Neu5Ac-6'-Neu5Ac-galactotriose (A30) and 3"'Neu5Gc-6'Neu5Gc-galactotriose (A33)) were identified. These isomers have not been detected in human milk $^{(7)}$ and had $\operatorname{Gal}(\beta 1-3)$ $\mathrm{Gal}(\beta 1-4)$ Glc backbone structures as revealed by sialidase digestion. Trace amounts of a galactotriose decorated with hexuronic acid were observed in camel milk (A24). As hexuronic acid is not a common milk oligosaccharide component, the oligosaccharide was assumed to be a degradation product or of different origin. In animal milk, two sialylated hexosaminyllactoses ( $3^{\prime} / 6^{\prime}$-Neu5Ac-hexosaminyl-lactose, A10 and A14) were also identified.

Sialylated lacto-N-neo-tetraose. In animal milk, $3^{\prime} / 6^{\prime}$ Neu5Ac-LNnT (A22/A26, the $6^{\prime}$-isomer has been identified previously in human milk ${ }^{(7)}$ ) was identified and traces of a Neu5Gc-LNnT isomer (A29) were also observed.

Sialylated lacto-N-novo-pentaose and lacto- $N$-neo-hexaose. In the present study, fourteen monosialylated and disialylated isomers and derivatives of $\mathrm{LNnP}$ and $\mathrm{LNnH}$ were observed in the milk of different animals (A27, A32 and A34-A45, with 6 '-sialyl-lacto- $N$-neo-hexaose (SLNnH) (A37) also being identified previously in human $\left.\operatorname{milk}^{(7)}\right)$. The sialic acid residues are exclusively attached to the non-reducing terminal Gal units and located on different sugars in case of disialylation.

\section{Structural characterisation of phosphorylated oligosaccharides in domestic animal milk}

Phosphorylated oligosaccharides were identified with the help of a phosphatase sourced from calf intestine. To include oligosaccharides that are phosphorylated at the 1-O position of the reducing end sugar, the acidic oligosaccharide pools were incubated with calf-intestinal alkaline phosphatase before and after labelling the reducing end with fluorescent 2-AB. Glycans resulting from enzymatic digestion could be identified by their GU values in the UPLC-HILIC-FLD profiles. In contrast to human milk oligosaccharides, for which phosphorylation has not been observed ${ }^{(7)}$, three phosphorylated structures were identified in animal milk in the present study (Table 3), namely $\mathrm{N}$-acetyl-lactosamine-1-O-phosphate (P1), $\mathrm{N}$-acetyllactosamine phosphate with phosphate group attached to a non-reducing position (P2) and lactose phosphate (P3).

\section{Discussion}

A structural library of neutral, fucosylated, sialylated and phosphorylated oligosaccharides from bovine, caprine, ovine, porcine, equine and dromedary camel milk was established in the present study. A total of forty-eight structures were identified in camel milk and forty-one structures were characterised in caprine milk. Furthermore, forty structures could be assigned for porcine and equine milk and thirtyeight and thirty-five structures were identified in ovine and bovine milk, respectively (Tables $1-4$ ). Many of these oligosaccharides have not been reported previously, and many more could be present as it was not possible to assign all minor peaks, which accounted for less than $1 \%$ of the total oligosaccharide content. Indeed, supplementary structures have been reported previously ${ }^{(5,10,17)}$. This is particularly the case for bovine milk, which has been extensively studied and for which more than fifty structures have been identified, including interesting novel fucosylated structures present 
Table 2. Structures and their relative abundances in the acidic oligosaccharide pools from animal milk

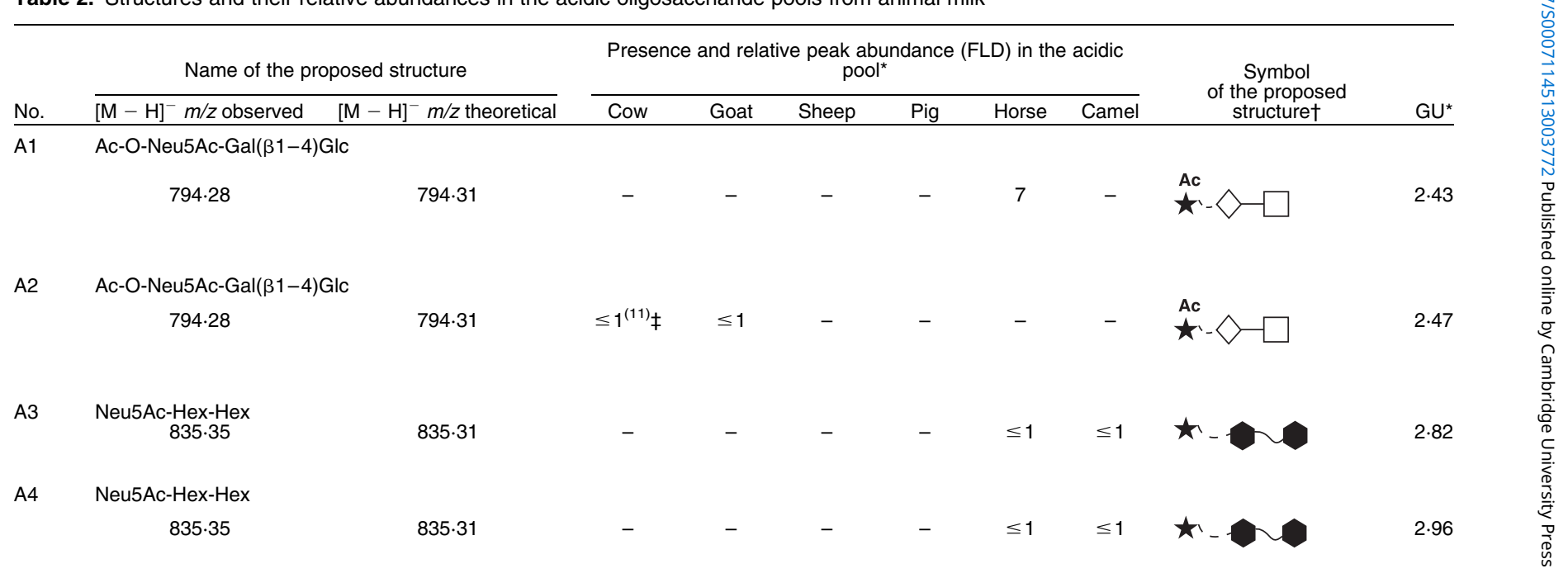

A5 Neu5Ac $(\alpha 2-3) \mathrm{Gal}(\beta 1-4) \mathrm{GICNAc}\left(3^{\prime}-\mathrm{SLN}\right)$ 793.33
$793 \cdot 30$

A6§ Neu5Ac $(\alpha 2-3) \mathrm{Gal}(\beta 1-4) \mathrm{Glc}\left(3^{\prime}-\mathrm{SL}\right)$ $752 \cdot 29$ $\leq 1^{(12)} \quad \leq 0 \cdot 1^{(8)} \quad \leq 0.1 \quad \leq 1^{(13)} \quad 2 \quad \leq 1$<smiles>[14CH3]</smiles>
3.04 $\mathrm{Neu} 5 \mathrm{Gc}(\alpha 2-3) \mathrm{Gal}(\beta 1-4) \mathrm{GlcNAc}\left(3^{\prime}-\mathrm{GLN}\right)$
809.34
$809 \cdot 29$

A8 Neu5Ac $(\alpha 2-6) \mathrm{Gal}(\beta 1-4) \mathrm{GlcNAc}\left(6^{\prime}-\mathrm{SLN}\right)$ 793.33
793.30 $75^{(11)} \quad 13^{(8)} \quad 4^{(35)} \quad 51^{(13)} \quad 81^{(36)} \quad 70^{(14)}$<smiles>[CH][CH]O</smiles>

A9 Neu5Gc $(\alpha 2-3) \mathrm{Gal}(\beta 1-4) \mathrm{Glc}\left(3^{\prime}-\mathrm{GL}\right)$ $(\alpha 2-3) \mathrm{Gal}(\beta 1-4) \mathrm{Glc}\left(3^{\prime}-\mathrm{GL}\right)$
$768 \cdot 30$ $\leq 1^{(11)} \quad 30^{(8)} \quad 70^{(35)} \quad \leq 1 \quad \leq 1 \quad \leq 1$<smiles>[C+]=CO[Tl]</smiles>
$\begin{array}{rr}\text { A10 } & \operatorname{Neu} 5 A c(\alpha 2-6) \operatorname{GlcNAc}(\beta 1-6) \mathrm{Gal}(\beta 1-4) \mathrm{Glc} \\ 955.34 & 955.35\end{array}$

A11§ Neu5Ac $(\alpha 2-6) \mathrm{Gal}(\beta 1-4) \mathrm{Glc}\left(6^{\prime}-\mathrm{SL}\right)$ $752 \cdot 29_{752 \cdot 27}$

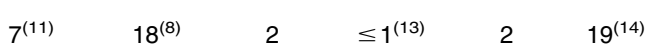<smiles>CC1CCC1C1CCC1</smiles>

A12 Neu5Ac( $\alpha 2-3) \operatorname{Gal}(\beta 1-4)(\operatorname{Fuc}(\alpha 1-3)) G l c$

$898 \cdot 36$

$898 \cdot 33$

A13 Neu5Gc $(\alpha 2-6)$ Gal $(\beta 1-4)$ GlcNAc $\left(6^{\prime}-G L N\right)$ $809 \cdot 34$

$809 \cdot 29$

$$
\leq 1^{(11)}
$$$$
2 \leq 1
$$

$\not 2$

A14 Neu5Ac $(\alpha 2-3) \operatorname{GlcNAc}(\beta 1-3) \mathrm{Gal}(\beta 1-4) \mathrm{Glc}$ $955 \cdot 34$ $955 \cdot 35$

$$
\leq 1^{(38)}
$$$$
\leq 1
$$$$
\leq 0 \cdot 1
$$$$
\leq 1^{(11)} \quad 27^{(8)} \quad 17^{(35)}
$$

A15 Neu5Gc( $\alpha 2-6)$ Gal $(\beta 1-4)$ Glc $\left(6^{\prime}-G L\right)$

$768 \cdot 30$

$768 \cdot 27$ 
Table 2. Continued

\begin{tabular}{|c|c|c|c|c|c|c|c|c|c|c|}
\hline \multirow[b]{2}{*}{ No. } & \multicolumn{2}{|c|}{ Name of the proposed structure } & \multicolumn{6}{|c|}{$\begin{array}{l}\text { Presence and relative peak abundance (FLD) in the acidic } \\
\text { pool* }^{\star}\end{array}$} & \multirow{2}{*}{$\begin{array}{c}\text { Symbol } \\
\text { of the proposed } \\
\text { structure } \dagger\end{array}$} & \multirow[b]{2}{*}{$\mathrm{GU}^{*}$} \\
\hline & {$[\mathrm{M}-\mathrm{H}]^{-} \mathrm{m} / \mathrm{z}$ observed } & {$[\mathrm{M}-\mathrm{H}]^{-} m / z$ theoretical } & Cow & Goat & Sheep & Pig & Horse & Camel & & \\
\hline A16 & \multicolumn{10}{|c|}{$\operatorname{Neu} 5 \mathrm{Ac}(\alpha 2-3) \mathrm{Gal}(\beta 1-3) \mathrm{Gal}(\beta 1-4) \mathrm{Glc}$} \\
\hline & $914 \cdot 36$ & $914 \cdot 33$ & $\leq 1^{(39)}$ & $\leq 1^{(40)}$ & $\leq 1$ & $\leq 1$ & $\leq 1$ & $4^{(14)}$ & & $4 \cdot($ \\
\hline
\end{tabular}

A17 Neu5Gc $(\alpha 2-3) \mathrm{Gal}(\beta 1-3) \mathrm{Gal}(\beta 1-4) \mathrm{Glc}$

$930 \cdot 38$

Glc

A18 $\operatorname{Gal}(\beta 1-3)(\operatorname{Neu} 5 \mathrm{Ac}(\alpha 2-6)) \mathrm{Gal}(\beta 1-4) \mathrm{Glc}$

$$
914.36 \quad 914.33
$$

$4 \cdot 33$

A19 Gal $(\beta 1-3)(\operatorname{Neu} 5 \mathrm{Gc}(\alpha 2-6)) \mathrm{Gal}(\beta 1-4) \mathrm{Glc}$

$930 \cdot 38$

$930 \cdot 32$

A20 Neu5Ac $(\alpha 2-8) \mathrm{Neu} 5 \mathrm{Ac}(\alpha 2-3) \mathrm{Gal}(\beta 1-4) \mathrm{GlcNAc}$ (DSLN)

A21 Neu5Ac $(\alpha 2-8) \operatorname{Neu} 5 \mathrm{Ac}(\alpha 2-3) \mathrm{Gal}(\beta 1-4) \mathrm{Glc}(\mathrm{DSL})$

$\begin{array}{llllll}1043.41 & 6^{(11)} & \leq 1^{(8)} & \leq 1 & - & 2\end{array}$

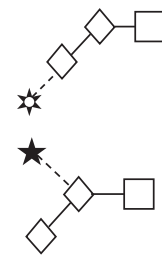

$4 \cdot 16$

A22 Neu5Ac $(\alpha 2-3) \operatorname{Gal}(\beta 1-4) \operatorname{GlcNAc}(\beta 1-3) \operatorname{Gal}(\beta 1-4) \mathrm{Glc}\left(3^{\prime}-\mathrm{SLNnT}\right)$

$1117 \cdot 45$

$\leq 1^{(39)}$

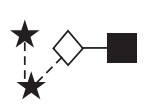

$4 \cdot 44$

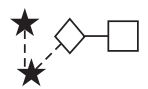

4.57

$$
1117 \cdot 40
$$

A23 Neu5Gc $(\alpha 2-8) \operatorname{Neu} 5 \mathrm{Ac}(\alpha 2-3) \mathrm{Gal}(\beta 1-4) \mathrm{Glc}(\mathrm{GSL})$

$1059 \cdot 43$

$1059 \cdot 36$

$\leq 1^{(11)} \quad \leq 1^{(8)} \quad \leq 1$

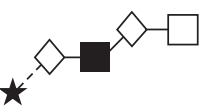

$4 \cdot 62$

A24 HexAc-Gal-Gal( $\beta 1-4) G l c$

$799 \cdot 27$

$799 \cdot 26$

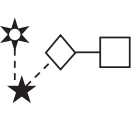

A25 Neu5Gc( $\alpha 2-8) \operatorname{Neu} 5 \mathrm{Gc}(\alpha 2-3) \mathrm{Gal}(\beta 1-4) \mathrm{Glc}(\mathrm{DGL})$

$$
1075 \cdot 40
$$

$1075 \cdot 36$

$$
\leq 1
$$<smiles></smiles>

A26§ Neu5Ac $(\alpha 2-6) \operatorname{Gal}(\beta 1-4) \operatorname{GlcNAc}(\beta 1-3) \operatorname{Gal}(\beta 1-4) \mathrm{Glc}\left(6^{\prime}-\mathrm{SLNnT}\right)$

$$
1117 \cdot 45
$$

$1117 \cdot 40$

$\operatorname{Neu} 5 A c(\alpha 2-3) \operatorname{Gal}(\beta 1-4) \operatorname{GlcNAc}(\beta 1-6)(\operatorname{GlcNAc}(\beta 1-3)) \mathrm{Gal}(\beta 1-4) \mathrm{Glc}$ $1320 \cdot 40$ $1320 \cdot 48$

Neu5Gc-Neu5Gc-Gal( $\beta 1-4)$ Glc (DGL)

$$
1075.40
$$

$1075 \cdot 36$

Neu5Gc + Gal $(\beta 1-4) G I c N A c(\beta 1-3) G a l(\beta 1-4) G l c(G L N n T)$

1133.43

1133.40$$
\leq 0 \cdot 1
$$$$
\leq 0 \cdot 1
$$<smiles>[Z17]C(C)(C)C1(CC)CCC1</smiles> 
Table 2. Continued

\begin{tabular}{|c|c|c|c|c|c|c|c|c|c|c|}
\hline \multirow[b]{2}{*}{ No. } & \multicolumn{2}{|c|}{ Name of the proposed structure } & \multicolumn{6}{|c|}{$\begin{array}{l}\text { Presence and relative peak abundance (FLD) in the acidic } \\
\text { pool }^{*}\end{array}$} & \multirow{2}{*}{$\begin{array}{c}\text { Symbol } \\
\text { of the proposed } \\
\text { structure }\end{array}$} & \multirow[b]{2}{*}{$\mathrm{GU}^{*}$} \\
\hline & {$[\mathrm{M}-\mathrm{H}]^{-} \mathrm{m} / \mathrm{z}$ observed } & {$[\mathrm{M}-\mathrm{H}]^{-} \mathrm{m} / \mathrm{z}$ theoretical } & Cow & Goat & Sheep & Pig & Horse & Camel & & \\
\hline \multirow[t]{2}{*}{ A30 } & $\operatorname{Neu} 5 A c(\alpha 2-3) \operatorname{Gal}(\beta 1-3$ & Neu5Ac( $\alpha 2-6)) \mathrm{Gal}(\beta 1-4)$ & & & & & & & & \\
\hline & $602 \cdot 21 \|$ & $602 \cdot 21 \|$ & $\leq 0.1$ & - & - & $\leq 1$ & $\leq 0.1$ & $\leq 1$ & & 5.48 \\
\hline
\end{tabular}

A31 Neu5Gc-Neu5Gc-Gal( $(\beta 1-4)$ Glc (DGL)

1075.40

A32 Neu5Ac( $\alpha 2-3)+\operatorname{Gal}(\beta 1-4) \operatorname{GlcNAc}(\beta 1-6)(\operatorname{Gal}(\beta 1-3)) \operatorname{Gal}(\beta 1-4) G l c(3-S L N n P ~ I)$

$1279.48 \quad 1279.46 \quad \leq 1^{(11)} \quad-\quad-\quad \leq 1^{(13)} \leq 1 \leq 1$

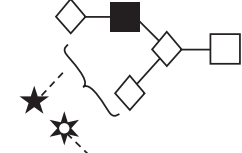

A33 Neu5Gc $(\alpha 2-3) G a l(\beta 1-3)(\operatorname{Neu} 5 G c(\alpha 2-6)) G a l(\beta 1-4) G l c$<smiles>C#CCC(C)CC</smiles>

A34 Neu5Ac $(\alpha 2-6)+\operatorname{Gal}(\beta 1-4) \operatorname{GlcNAc}(\beta 1-6)(\operatorname{Gal}(\beta 1-3))$ Gal $(\beta 1-4)$ Glc (6-SLNnP I)

$1279 \cdot 48$

$1279 \cdot 46$

$\leq 0 \cdot 1^{(11)}$

$\leq 0$

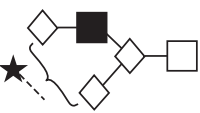

$6 \cdot 38$

A35

Neu5Ac $(\alpha 2-3)+\operatorname{Gal}(\beta 1-4) \operatorname{GlcNAc}(\beta 1-6)(\operatorname{Gal}(\beta 1-4) \operatorname{GlcNAc}(\beta 1-3)) \operatorname{Gal}(\beta 1-4)$ Glc (3-SLNnH)

$1482 \cdot 56$

1482.54

$\leq 1^{(1)}$

$-$

$\leq 1^{(13)}$

$\leq 0$.

$\leq 0.1$

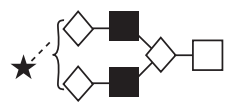

6.44

A36 Neu5Gc $(\alpha 2-3)+\operatorname{Gal}(\beta 1-4) \operatorname{GlcNAc}(\beta 1-6)(\operatorname{Gal}(\beta 1-3)) \operatorname{Gal}(\beta 1-4) G \mid c(3 G L N n P I)$

$1295 \cdot 59$

1295.45

$\leq 0.1 \leq 0.1$

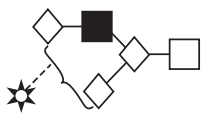

6.42

A37§ Neu5Ac $(\alpha 2-6)+\operatorname{Gal}(\beta 1-4) \operatorname{GlcNAc}(\beta 1-6)(\operatorname{Gal}(\beta 1-4) \operatorname{GlcNAc}(\beta 1-3)) \operatorname{Gal}(\beta 1-4) \operatorname{Glc}(6-S L N n H)$

1482.56

1482.54

$\leq 1^{(11)}$

$-$

$-$

$4^{(13)}$

$\leq 1 \quad \leq 1^{(14)}$

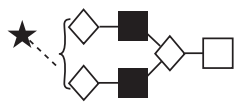

$6 \cdot 83$

A38 Neu5Gc $(\alpha 2-6)+\operatorname{Gal}(\beta 1-4) \operatorname{GlcNAc}(\beta 1-6)(\operatorname{Gal}(\beta 1-3)) \operatorname{Gal}(\beta 1-4) G l c(6 G L N n P$ I)

1295.59

$1295 \cdot 45$

A39

Neu5Gc $(\alpha 2-3)+\operatorname{Gal}(\beta 1-4) \operatorname{GlcNAc}(\beta 1-6)(\operatorname{Gal}(\beta 1-4) \operatorname{GlcNAc}(\beta 1-3)) \operatorname{Gal}(\beta 1-4)$ Glc $(3-G L N n H)$
$1295 \cdot 59$ (1)

1498.53

1498.53

A40

$2 \mathrm{Neu} 5 \mathrm{Ac}+\mathrm{Gal}(\beta 1-4) \mathrm{GlcNAc}(\beta 1-6)(\mathrm{Gal}(\beta 1-3)) \mathrm{Gal}(\beta 1-4) \mathrm{Glc}(\mathrm{DSLNnP} \mathrm{I})$ 
Table 2. Continued

\begin{tabular}{|c|c|c|c|c|c|c|c|c|c|c|}
\hline \multirow[b]{2}{*}{ No. } & \multicolumn{2}{|c|}{ Name of the proposed structure } & \multicolumn{6}{|c|}{$\begin{array}{l}\text { Presence and relative peak abundance (FLD) in the acidic } \\
\text { pool }^{*}\end{array}$} & \multirow{2}{*}{$\begin{array}{c}\text { Symbol } \\
\text { of the proposed } \\
\text { structure } \dagger\end{array}$} & \multirow[b]{2}{*}{$\mathrm{GU}^{*}$} \\
\hline & {$[\mathrm{M}-\mathrm{H}]^{-} \mathrm{m} / \mathrm{z}$ observed } & {$[\mathrm{M}-\mathrm{H}]^{-} \mathrm{m} / \mathrm{z}$ theoretical } & Cow & Goat & Sheep & Pig & Horse & Camel & & \\
\hline A41 & \multicolumn{9}{|c|}{ 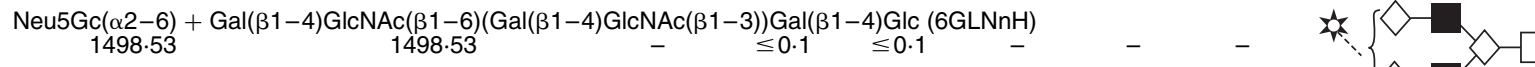 } & $7 \cdot 29$ \\
\hline \multirow[t]{2}{*}{ A42 } & \multicolumn{8}{|c|}{$2 N e u 5 A c+\operatorname{Gal}(\beta 1-4) \operatorname{GlcNAc}(\beta 1-6)(\mathrm{Gal}(\beta 1-3)) \mathrm{Gal}(\beta 1-4) \mathrm{Glc}(\mathrm{DSLNnP} \mathrm{I})$} & & \\
\hline & $784 \cdot 78 \|$ & $784 \cdot 77 \|$ & $\leq 1$ & - & - & $\leq 1 q^{(13)}$ & - & - & & $7 \cdot 41$ \\
\hline \multirow[t]{2}{*}{ A43 } & \multicolumn{8}{|c|}{$2 \mathrm{Neu} 5 \mathrm{Ac}+\mathrm{Gal}(\beta 1-4) \mathrm{GlcNAc}(\beta 1-6)(\mathrm{Gal}(\beta 1-4) \mathrm{GlcNAc}(\beta 1-3)) \mathrm{Gal}(\beta 1-4) \mathrm{Glc}(\mathrm{DSLNnH})$} & & \\
\hline & $886 \cdot 32 \|$ & $886 \cdot 31 \|$ & $\leq 1$ & - & - & $\leq 1 q^{(13)}$ & - & - & & $7 \cdot 41$ \\
\hline \multirow[t]{2}{*}{ A44 } & \multicolumn{8}{|c|}{$2 N e u 5 A c+\operatorname{Gal}(\beta 1-4) \operatorname{GlcNAc}(\beta 1-6)(\operatorname{Gal}(\beta 1-4) \operatorname{GlcNAc}(\beta 1-3)) G a l(\beta 1-4) G l c(D S L N n H)$} & & \\
\hline & $886 \cdot 32 \|$ & $886 \cdot 31 \|$ & - & - & - & - & $\leq 0.1$ & - & & $7 \cdot 76$ \\
\hline \multirow[t]{2}{*}{ A45 } & \multicolumn{8}{|c|}{ Neu5Ac $+\operatorname{Gal}(\alpha 1-3)+\operatorname{Gal}(\beta 1-4) \operatorname{GlcNAc}(\beta 1-6)(\operatorname{Gal}(\beta 1-4) \operatorname{GlcNAc}(\beta 1-3)) \operatorname{Gal}(\beta 1-4) \mathrm{Glc}$} & & \\
\hline & 1644.59 & $1644 \cdot 62$ & - & - & - & $\leq 1$ & - & - & & $7 \cdot 76$ \\
\hline
\end{tabular}

FLD, fluorescence detection; GU, glucose unit reference values; Neu5Ac, N-acetylneuraminic acid; Gal, galactose; Glc, glucose; GlcNAc, N-acetyl-glucosamine; SLN, sialylated $\mathrm{N}$-acetyllactosamine; SL, sialyllactose; Neu5Gc, $\mathrm{N}$-glycolylneuraminic acid; GLN, glycolyl- $N$-acetyllactosamine; GL, glycoyl-lactose; Fuc, fucose; DSLN, disialyl- $N$ acetyllactosamine; DSL, disialyl-lactose; SLNnT, sialyl-lacto- $N$-neo-tetraose; GSL, glycolyl-sialyl-lactose; HexAc, hexuronic acid; DGL, diglycolyl-lactose; GLNnT, glycolyllacto- $N$-neo-teraose; SLNnP, sialyl-lacto- $N$-neo-pentaose; SLNnH, sialyl-lacto- $N$-neo-hexaose; GLNnP, glycolyl-lacto- $N$-neo-pentaose; GLNnH, glycolyl-lacto- $N$-neo-hexaose; DSLNnP, disialyl-lacto- $N$-neo-pentaose; DSLNnH, sialyl-lacto- $N$-neo-hexaose.

${ }^{*}$ Relative peak area and GU correspond to the average (av) observed for the respective species, which were each analysed in duplicate or triplicate $\left(\Delta G U_{(a v)} \leq 0.03\right)$.

† Oxford symbol nomenclature ${ }^{(30)}$ (Fig. 1(b)).

$\ddagger$ Most recent reference was included for identified structures that were previously assigned for the respective milk samples.

$\S$ Structures also reported for human milk $^{(6,7)}$.

$\| m / z$ observed $\left([\mathrm{M}-2 \mathrm{H}]^{2-}\right)$.

I Co-eluting structures; relative abundance accounts for both structures.

in minor proportions ${ }^{(10,11)}$. The qualitative and quantitative composition of oligosaccharides in animal milk is variable and complicates the comparison between different studies and species. On the one hand, variations might be due to the use of different analytical techniques and oligosaccharide extraction methods. On the other hand, the milk oligosaccharide composition is subject to genetic variation, and the number and concentration of glycans decrease rapidly over the course of lactation ${ }^{(22,23)}$. The most significant decrease in bovine colostrum oligosaccharides can be observed during the first $12-24 \mathrm{~h}$ after calving ${ }^{(9,22)}$. In particular, a shift towards a higher percentage of neutral glycans is observed in time. Whereas sialylation is $>80 \%$ in bovine colostrums, it decreases to approximately $40 \%$ in milk collected after $6 \mathrm{~d}^{(22)}$. Representative pools of colostrum milk $(n \geq 3)$ were used in the present study, except for camels and goats, for which pooled mature milk $(n \geq 3)$ was used. Indeed, twenty-three of the forty-five structures identified for camel milk belonged to the neutral oligosaccharide fraction, which had the highest number of neutral glycans observed for all the animal species in the present study and which might be due to the use of mature milk instead of colostrum. However, for mature

Table 3. Qualitative presence of phosphorylated oligosaccharides in the acidic oligosaccharide pools from animal milk

\begin{tabular}{|c|c|c|c|c|c|c|c|c|}
\hline \multirow[b]{2}{*}{ No. } & \multirow[b]{2}{*}{ Name of the proposed structure } & \multicolumn{6}{|c|}{ Presence $(X)$ in the acidic pool } & \multirow[b]{2}{*}{ Symbol of the proposed structure } \\
\hline & & Bovine & Goat & Sheep & Pig & Horse & Camel & \\
\hline P1 & Gal( $\beta 1-4)$ GlcNAc-O-P & - & - & $x$ & - & $x^{(36)} \dagger$ & $x$ & $\diamond$ \\
\hline P2 & $P+G a l(\beta 1-4) G l c N A c$ & $x$ & - & - & - & - & - & \\
\hline P3 & $P+\operatorname{Gal}(\beta 1-4) G l c$ & $X^{(41)}$ & $x$ & $x$ & - & $x$ & $x$ & \\
\hline
\end{tabular}

Gal, galactose; GlcNAc, $N$-acetyl-glucosamine; P, phosphate.

* Oxford symbol nomenclature ${ }^{(30)}$ (Fig. 1(b)).

† Most recent reference was included for identified structures that were previously assigned for the respective milk samples. 
Table 4. Overview of glycan structures in the milk of domestic animals identified in the present study (Number of structures and percentages)

\begin{tabular}{|c|c|c|c|c|c|c|c|c|c|c|c|c|}
\hline & \multicolumn{2}{|c|}{ Bovine } & \multicolumn{2}{|c|}{ Goat } & \multicolumn{2}{|c|}{ Sheep } & \multicolumn{2}{|r|}{ Pig } & \multicolumn{2}{|c|}{ Horse } & \multicolumn{2}{|c|}{ Camel } \\
\hline & $n$ & $\%$ & $n$ & $\%$ & $n$ & $\%$ & $n$ & $\%$ & $n$ & $\%$ & $n$ & $\%$ \\
\hline \multicolumn{13}{|l|}{ Total UPLC-HILIC-FLD oligosaccharide profile } \\
\hline $\begin{array}{r}\text { Peak area for neutral } \\
\text { oligosaccharides }\end{array}$ & & 9 & & 5 & & 14 & & 18 & & 10 & & 16 \\
\hline $\begin{array}{l}\text { Peak area for acidic } \\
\text { oligosaccharides }\end{array}$ & & 91 & & 95 & & 86 & & 82 & & 90 & & 84 \\
\hline $\begin{array}{l}\text { Total number of structures } \\
\text { identified (neutral }+ \text { acidic }+ \text { phosphorylated) }\end{array}$ & 35 & & 40 & & 37 & & 39 & & 40 & & 45 & \\
\hline $\begin{array}{l}\text { New structures identified for } \\
\text { this species }\end{array}$ & 5 & & 19 & & 31 & & 20 & & 32 & & 38 & \\
\hline $\begin{array}{l}\text { Structures in the neutral } \\
\text { oligosaccharide pool }\end{array}$ & 12 & & 16 & & 16 & & 19 & & 17 & & 23 & \\
\hline $\begin{array}{l}\text { Number and peak area of fucosylated } \\
\text { structures in the neutral } \\
\text { oligosaccharide pool }\end{array}$ & 3 & 6 & 3 & 5 & 3 & 3 & 3 & 3 & $2^{*}$ & $<1$ & 7 & 6 \\
\hline $\begin{array}{l}\text { Structures in the acidic } \\
\text { oligosaccharide pool }\end{array}$ & 21 & & 23 & & 19 & & 20 & & 21 & & 20 & \\
\hline $\begin{array}{l}\text { Number and peak area of large } \\
\text { structurest in the acidic oligosaccharide } \\
\text { pool }\end{array}$ & 6 & 1 & 4 & $<1$ & 3 & $<1$ & 9 & 10 & 6 & 1 & 3 & 1 \\
\hline Phosphorylated structures & 2 & & 1 & & 2 & & - & & 2 & & 2 & \\
\hline $\begin{array}{l}\text { Structures also present in } \\
\text { human milk } \\
\text { Sialic acid composition (DMB } \\
\text { speciation) }\end{array}$ & 8 & & 8 & & 8 & & 11 & & 8 & & 12 & \\
\hline Proportion of Neu5Ac/Neu5Gc & & $97 / 3$ & & $36 / 64$ & & $6 / 94$ & & $99 \cdot 9 / 0 \cdot 1$ & & $99 / 1$ & & $99 \cdot 7 / 0 \cdot 3$ \\
\hline
\end{tabular}

caprine milk, the number and percentage of neutral oligosaccharides were comparable with what was found for colostrum milk from other animal species.

Our comparative analysis revealed not only many similarities but also species-specific characteristics. Sialylated oligosaccharides accounted for approximately $80-90 \%$ of the total oligosaccharide pools from the milk of all domestic animals. The neutral and acidic oligosaccharides from bovine, caprine and ovine milk were mainly of short chain length. The proportion of Neu5Gc-containing oligosaccharides in the acidic oligosaccharide fraction of caprine (64\%) and ovine (94\%) milk was highest, whereas only traces of Neu5Gc-containing oligosaccharides were observed in the milk from pigs and camels. Compared with the milk from other animal species, that from horses and camels contained a more balanced mixture of shorter and larger oligosaccharides. Interestingly, milk oligosaccharides from dromedary camels were exceptionally diverse and included seven fucosylated structures. The oligosaccharide mixture in porcine milk is unique. Among all the milk samples of the domestic animal species investigated, porcine milk contained the highest percentage of neutral oligosaccharides (approximately $20 \%$ ) and the most abundant variety of monosialylated and disialylated large oligosaccharides. Porcine milk oligosaccharides come closest to the human milk oligosaccharide mixture, which clearly demonstrates that milk oligosaccharides are tailor-made for the postnatal development of certain gastrointestinal systems and that these molecules aid in the preparation for certain post-weaning diets by acting as early dietary fibres. Humans and pigs are monogastric and therefore large bowel fermenters, whereas cows, goats and sheep are ruminants; camels have a three-chambered digestive system and horses have an extended caecal digestive system. Furthermore, humans and pigs are omnivores, whereas all other species are herbivores. Pigs are considered to be excellent models for human large bowel fibre metabolism, and the similarity between the human and porcine milk glycomes reinforces their usefulness in studying early-life nutritional programming and development of the gastrointestinal system $^{(24,25)}$.

The present study further highlights the distinct difference between the nature and number of oligosaccharides in human and domestic animal milk, in general, with merely thirteen common oligosaccharides (Tables 1-4). Different from domestic animal milk oligosaccharides, approximately $70 \%$ of the human milk oligosaccharides are neutral and largely fucosylated. Human milk oligosaccharides contain neither Neu5Gc nor ( $\alpha 1-3)$-linked galactose, and these non-human structural components might cause immunogenic reactions upon human consumption ${ }^{(26,27)}$. In human milk, oligosaccharides of the lacto- $N$-biose type I structure (Gal( $\beta 1-3)$ GlcNAc) predominate over those containing the $N$-acetyllactosamine type II structure (Gal( $\beta 1-4)$ GlcNAc). The milk of domestic animals contains exclusively type II oligosaccharides. In the milk of few other species, such as chimpanzees and elephants, type I oligosaccharides predominate over type $\mathrm{II}^{(28,29)}$. Type I oligosaccharides are specific for human milk and may serve as substrates for beneficial bifidobacteria in breast-fed infants ${ }^{(29)}$. 
Despite the obvious differences between animal and human milk oligosaccharides, the present study clearly demonstrates that milk from domestic animals contains a much larger variety of complex oligosaccharides than previously thought. Therefore, domestic animal milk is a highly attractive source of bioactive oligosaccharides, which once extracted can be potentially used in medical and functional foods. To justify their use, additional studies on their biological functions are required. The advanced knowledge on their structural composition will certainly help to gain new insights into the complex biochemical pathways underlying their potential healthpromoting properties.

\section{Acknowledgements}

The present study was carried out in the framework of the Alimentary Glycoscience Research Cluster. Galactotriose standards were kindly provided by Dr S. Austin (Nestlé Research Lausanne, Switzerland).

The present study was funded by Science Foundation Ireland (08/SRC/B1393). Science Foundation Ireland had no role in the design and analysis of the study or in the writing of this article.

The authors' contributions are as follows: S. A. carried out the sample analysis, interpreted the findings and prepared the manuscript; J. A. L. extracted the milk oligosaccharides from animal milk and K. M. contributed to the sample analysis; K. A. A. B. provided camel milk; S. D. C., R. M. H. and P. M. R. were scientific advisors; J. A. L., K. M., K. A. A. B., S. D. C., R. M. H. and P. M. R. carefully revised the manuscript.

None of the authors has any conflicts of interest to declare.

\section{References}

1. Bode L, Kunz C, Muhly-Reinholz M, et al. (2004) Inhibition of monocyte, lymphocyte, and neutrophil adhesion to endothelial cells by human milk oligosaccharides. Thromb Haemost 92, 1402-1410.

2. Hickey RM (2012) The role of oligosaccharides from human milk and other sources in prevention of pathogen adhesion. Int Dairy J 22, 141-146.

3. Lane JA, Mariño K, Naughton J, et al. (2012) Anti-infective bovine colostrum oligosaccharides: Campylobacter jejuni as a case study. Int J Food Microbiol 157, 182-188.

4. Wang B, Yu B, Karim M, et al. (2007) Dietary sialic acid supplementation improves learning and memory in piglets. Am J Clin Nutr 85, 561-569.

5. Urashima T, Saito T, Nakamura T, et al. (2001) Oligosaccharides of milk and colostrum in non-human mammals. Glycoconj J 18, 357-371.

6. Niñonuevo MR, Park Y, Yin HF, et al. (2006) A strategy for annotating the human milk glycome. J Agric Food Chem 54, 7471-7480.

7. Urashima T, Asakuma S \& Messer M (2007) Milk oligosaccharides. In Comprehensive Glycoscience. From Chemistry to System Biology, pp. 695-722 [JP Kamerling, GJ Boons, YC Lee, A Suzuki, N Taniguchi and AGJ Voragen, editors]. Oxford, UK: Elsevier.

8. Martinez-Ferez A, Rudloff S, Guadix A, et al. (2006) Goats' milk as a natural source of lactose-derived oligosaccharides: isolation by membrane technology. Int Dairy J 16, 173-181.
9. Nakamura T, Kawase H, Kimura K, et al. (2003) Concentrations of sialyloligosaccharides in bovine colostrum and milk during the prepartum and early lactation. J Dairy Sci 86, 1315-1320.

10. Aldredge DL, Geronimo MR, Hua S, et al. (2013) Annotation and structural elucidation of bovine milk oligosaccharides and determination of novel fucosylated structures. Glycobiology 23, 664-676.

11. Mariño K, Lane JA, Abrahams JL, et al. (2011) Method for milk oligosaccharide profiling by 2-aminobenzamide labeling and hydrophilic interaction chromatography. Glycobiology 21, $1317-1330$.

12. Tao N, Depeters EJ, Freeman S, et al. (2008) Bovine milk glycome. J Dairy Sci 91, 3768-3778.

13. Tao N, Ochonicky KL, German JB, et al. (2010) Structural determination and daily variations of porcine milk oligosaccharides. J Agric Food Chem 58, 4653-4659.

14. Alhaj OA, Taufik E, Handa Y, et al. (2013) Chemical characterisation of oligosaccharides in commercially pasteurised dromedary camel (Camelus dromedarius) milk. Int Dairy J 28, 70-75.

15. Urashima T, Saito T \& Kimura T (1991) Chemical structures of three neutral oligosaccharides obtained from horse (thoroughbred) colostrum. Comp Biochem Physiol B - Biochem Mol Biol 100, 177-183.

16. Urashima T, Sakamoto T, Ariga H, et al. (1989) Structure determination of three neutral oligosaccharides obtained from horse colostrum. Carbohydr Res 194, 280-287.

17. Urashima T, Taufik E, Fukuda K, et al. (2013) Recent advances in studies on milk oligosaccharides of cows and other domestic farm animals. Biosci Biotechnol Biochem 77, 455-466.

18. Bradford MM (1976) Rapid and sensitive method for quantitation of microgram quantities of protein utilizing principle of protein-dye binding. Anal Biochem 72, 248-254.

19. Royle L, Dwek RA \& Rudd PM (2006) Determining the structure of oligosaccharides N- and O-linked to glycoproteins. In Current Protocols in Protein Science, p. Unit 12.06 S43 [JE Coligan, BM Dunn, DW Speicher and PT Wingfield, editors] New York: Wiley.

20. NIBRT GlycoBase 3.2 (2013) http://glycobase.nibrt.ie

21. Urashima T, Yamashita T, Nakamura T, et al. (2000) Chemical characterization of milk oligosaccharides of the polar bear, Ursus maritimus. Biochim Biophys Acta 1475, 395-408.

22. Barile D, Marotta M, Chu C, et al. (2010) Neutral and acidic oligosaccharides in Holstein-Friesian colostrum during the first 3 days of lactation measured by high performance liquid chromatography on a microfluidic chip and time-offlight mass spectrometry. J Dairy Sci 93, 3940-3949.

23. Tao N, De Peters EJ, German JB, et al. (2009) Variations in bovine milk oligosaccharides during early and middle lactation stages analyzed by high-performance liquid chromatography-chip/mass spectrometry. J Dairy Sci $\mathbf{9 2}$ 2991-3001.

24. Guilloteau P, Zabielski R, Hammon HM, et al. (2010) Nutritional programming of gastrointestinal tract development. Is the pig a good model for man? Nutr Res Rev 23, 4-22.

25. Topping DL \& Clifton PM (2001) Short-chain fatty acids and human colonic function: roles of resistant starch and nonstarch polysaccharides. Physiol Rev 81, 1031-1064.

26. Saleh H, Embry S, Nauli A, et al. (2012) Anaphylactic reactions to oligosaccharides in red meat: a syndrome in evolution. Clin Mol Allergy 10, 5.

27. Tangvoranuntakul P, Gagneux P, Diaz S, et al. (2003) Human uptake and incorporation of an immunogenic nonhuman 
dietary sialic acid. Proc Natl Acad Sci U S A 100, 12045-12050.

28. Kunz C, Rudloff S, Schad W, et al. (1999) Lactose-derived oligosaccharides in the milk of elephants: comparison with human milk. Br J Nutr 82, 391-399.

29. Urashima T, Asakuma S, Leo F, et al. (2012) The predominance of type I oligosaccharides is a feature specific to human breast milk. Adv Nutr 3, 473S-482S.

30. Harvey DJ, Merry AH, Royle L, et al. (2009) Proposal for a standard system for drawing structural diagrams of $\mathrm{N}$ - and O-linked carbohydrates and related compounds. Proteomics 9, 3796-3801.

31. Urashima T, Bubb WA, Messer M, et al. (1994) Studies of the neutral trisaccharides of goat (Capra hircus) colostrum and of the one-dimensional and two-dimensional ${ }^{1} \mathrm{H}$ and ${ }^{13} \mathrm{C}$ NMR-spectra of $6^{\prime}-N$-acetylglucosaminyllactose. Carbohydr Res 262, 173-184.

32. Saito T, Itoh T \& Adachi S (1987) Chemical structure of three neutral trisaccharides isolated in free form from bovine colostrum. Carbohydr Res 165, 43-51.

33. Urashima T, Saito T, Nishimura J, et al. (1989) New galactosyllactose containing alpha-glycosidic linkage isolated from ovine (Booroola Dorset) colostrum. Biochim Biophys Acta 992, 375-378.

34. Fukuda K, Yamamoto A, Ganzorig K, et al. (2010) Chemical characterization of the oligosaccharides in Bactrian camel
(Camelus bactrianus) milk and colostrum. J Dairy Sci 93, 5572-5587.

35. Nakamura T, Urashima T, Nakagawa M, et al. (1998) Sialyllactose occurs as free lactones in ovine colostrum. Biochim Biophys Acta 1381, 286-292.

36. Nakamura T, Amikawa S, Harada T, et al. (2001) Occurrence of an unusual phosphorylated $N$-acetyllactosamine in horse colostrum. Biochim Biophys Acta 1525, 13-18.

37. Urashima T, Murata S \& Nakamura T (1997) Structural determination of monosialyl trisaccharides obtained from caprine colostrum. Comp Biochem Physiol B - Biochem Mol Biol 116, 431-435.

38. Pan GG \& Melton LD (2005) Analysis of sialyl oligosaccharides by high-performance liquid chromatographyelectrospray ionisation-mass spectrometry with differentiation of alpha 2-3 and alpha 2-6 sialyl linkages. $J$ Chromatogr $A$ 1077, 136-142.

39. Parkkinen J \& Finne J (1987) Isolation of sialyl oligosaccharides and sialyl oligosaccharide phosphates from bovine colostrum and human urine. Method Enzymol 138, 289-300.

40. Viverge D, Grimmonprez L \& Solere M (1997) Chemical characterization of sialyl oligosaccharides isolated from goat (Capra hircus) milk. Biochim Biophys Acta 1336, 157-164.

41. Cumar FA, Ferchmin PA \& Caputto R (1965) Isolation and identification of a lactose phosphate ester from cow colostrum. Biochem Biophys Res Commun 20, 60-62. 